\title{
Efecto del ácido retinoico sobre la expresión del receptor CCR9 y la integrina alfa 4 beta 7 en leucocitos sanguíneos de alpacas (Vicugna pacos)
}

\author{
EFFECT OF RETINOIC CCID ON EXPRESSION OF RECEPTOR CCR9 AND ALPHA 4 BETA 7 \\ INTEGRIN IN ALPACA BLOOD LEUKOCYTES (Vicugna pacos)
}

Eduardo Hermoza C. ${ }^{1}$, Alberto Manchego S. ${ }^{1,4}$, Gina Castro S. ${ }^{1}$, Danilo Pezo C. ${ }^{3}$, Nieves Sandoval C. ${ }^{2}$

\section{Resumen}

\begin{abstract}
Las células T efectoras (CD4+ y CD8+) y de memoria pueden migrar a la mayoría de los tejidos extra-linfoides en el cuerpo, pero requieren la expresión de receptores de alojamiento (homing) específicos en las células T, la integrina $\alpha 4 \beta 7$ y el receptor de quimiocina CCR9. Los linfocitos circulantes CD4+ o CD8+ carecen de receptores CCR9 y $\alpha 4 \beta 7$; sin embargo, expresan este tipo de receptores al alcanzar la mucosa intestinal. El objetivo del estudio fue determinar el efecto del ácido retinoico sobre la expresión de los receptores CCR9 y la integrina $\alpha 4 \beta 7$ en linfocitos sanguíneos de alpacas (Vicugna pacos). Se realizó un análisis in vitro de muestra de sangre circulante de alpaca. Los leucocitos obtenidos se colocaron en placas de cultivo celular en medio esencial mínimo (MEM) suplementados e inoculados con ácido retinoico a concentraciones de 10, 50 y $100 \mathrm{ig} / \mathrm{ml}$ disuelto en DMSO. Se empleó un control a base de suero fisiológico. Las placas de cultivo celular fueron incubadas por 12,24 y 48 h a $37^{\circ} \mathrm{C}$ con $\mathrm{CO}_{2}$ al $5 \%$. Se realizó las PCR en Tiempo Real de los ARNm del receptor CCR9 y la integrina $\alpha 4 \beta 7$ y la cuantificación relativa con el método $2^{-\Delta \Delta \mathrm{Ct}}$. Las máximas expresiones para CCR9 se dieron a las $48 \mathrm{~h}$ para las concentraciones de 10 y $100 \mu \mathrm{g} / \mathrm{ml}$ de ácido retinoico y DMSO, y a las $24 \mathrm{~h}$ para la concentración de $50 \mu \mathrm{g} / \mathrm{ml}$. El control presentó expresiones mucho más elevadas en comparación con las dosis de ácido retinoico y DMSO. No hubo expresión para la integrina $\alpha 4 \beta 7$.
\end{abstract}

Palabras clave: CCR9; alfa4beta7; ácido retinoico; homing; intestino; alpacas

\footnotetext{
${ }^{1}$ Laboratorio de Microbiología y Parasitología Veterinaria, ${ }^{2}$ Laboratorio de Histología, Embriología y Patología Veterinaria, Facultad de Medicina Veterinaria, Universidad Nacional Mayor de San Marcos, Lima, Perú

${ }^{3}$ Estación Experimental del Centro de Investigación IVITA, Sede Maranganí, Universidad Nacional Mayor de San Marcos, Cusco, Perú

${ }^{4}$ E-mail: amanchegos@unmsm.edu.pe
}

Recibido: 1 de junio de 2017

Aceptado para publicación: 28 de noviembre de 2017 
Effector T cells (CD4+ and CD8+) and memory cells can migrate to most extra lymphoid tissues in the body, but require the expression of specific homing receptors in $\mathrm{T}$ cells, $\alpha 4 \beta 7$ integrin and receptor chemokine CCR9. CD4+ or CD8+ circulating lymphocytes lack CCR9 and $\alpha 4 \beta 7$ receptors; however, these receptors are expressed upon reaching the intestinal mucosa. The aim of the study was to determine the effect of retinoic acid on the expression of CCR9 receptors and $\alpha 4 \beta 7$ integrin on alpaca lymphocytes (Vicugna pacos). An in vitro analysis of circulating alpaca blood sample was performed. The obtained leukocytes were placed in cell culture plates in minimal essential medium (MEM) supplemented with retinoic acid at concentrations of 10, 50 and $100 \mathrm{ig} / \mathrm{ml} \mathrm{dissolved} \mathrm{in}$ DMSO. A control based on physiological serum was used. Cell culture plates were incubated for 12,24 and $48 \mathrm{~h}$ at $37{ }^{\circ} \mathrm{C}$ with $5 \% \mathrm{CO}_{2}$. Real-time PCR of the CCR9 receptor mRNA and $\alpha 4 \beta 7$ integrin and relative quantification with the $2^{-\Delta \Delta C t}$ method were performed. The maximum expressions for CCR9 were given at $48 \mathrm{~h}$ for concentrations of 10 and 100 $\mu \mathrm{g} / \mathrm{ml}$ of retinoic acid and DMSO, and at $24 \mathrm{~h}$ for the concentration of $50 \mu \mathrm{g} / \mathrm{ml}$. The control had much higher expressions compared to the doses of retinoic acid and DMSO. There was no expression for the $\alpha 4 \beta 7$ integrin.

Key words: CCR9; alfa4beta7; retinoic acid; homing; intestine; alpaca

\section{INTRODUCCIÓN}

Una de las principales limitantes para el buen desarrollo y crianza de la alpaca son los problemas entéricos de origen infeccioso que reducen la eficiencia productiva y que generan grandes pérdidas económicas a los criadores. Estos problemas entéricos son controlados por la inmunidad de la mucosa intestinal; sin embargo, es poco lo que se conoce sobre el desarrollo y establecimiento de la respuesta inmune de mucosas en alpacas y la manera que se puede incrementar esta respuesta.

Los linfocitos $\mathrm{T}$ que se dirigen al intestino expresan $\alpha 4 \beta 7$ y CCR9. Este mecanismo permite a las células migrar específicamente a sitios mucosos (gut homing). Esta migración de células hacia el intestino es influenciada por el receptor de quimiocina CCR9 y su ligando CCL25, expresado en el epitelio intestinal. El rodamiento de linfocitos en el endotelio intestinal está mediado por la integrina á4â7 expresada en linfocitos T y B de la lámina propia del tracto intestinal y su interacción con la molécula 1 de adhesión celular adhesina vascular mucosa (MAdCAM1), expresada en células endoteliales (Cassani et al., 2011). El ácido retinoico, compuesto derivado de la vitamina A producido a nivel de la mucosa intestinal, promueve la expresión de $\alpha 4 \beta 7$ y CCR9 en linfocitos $\mathrm{T}$ provocando su activación y marcación con el tropismo intestinal (Iwata et al., 2004).

El ácido retinoico regula las respuestas inmunes intestinales a través de acciones inmunomoduladoras sobre las células intestinales dendríticas (DCs) y linfocitos. Zeng et al. (2013) mostraron que el AR también controla la generación de precursores de DC migratorias intestinales, denominadas DCs pre-mucosales (pre-uDCs). Estas expresan el receptor intestinal $\alpha 4 \beta 7$ y se alojan preferentemente en el intestino. Se desarrollan en la médula ósea, pueden diferenciarse en células dendríticas plasmacitoides CCR9+, así como en CDs convencionales, pero preferentemente dan lugar a CDs intestinales 
CD103+. La generación de pre-uDCs in vivo en la médula ósea o in vitro está regulada por la señalización de ácido retinoico con su receptor RAR $\alpha$. La frecuencia de pre-u-DCs se reduce en animales con avitaminosis A y en animales tratados con inhibidores de RAR (Zeng et al., 2013).

El ácido retinoico regula directa e indirectamente la actividad de células $\mathrm{T}$ incluyendo la apoptosis inducida por activación y el desarrollo de linfocitos Th1 y Th2 (Iwata et al., 2004). El ATRA, o ácido retinoico alltrans, es un regulador transcripcional de células troncales hematopoyéticas al promover la retención de las mismas en cultivos celulares (Purton et al., 2000; Leung y Verfaillie, 2005). Se ha visto que el número de células madre hematopoyéticas fue bajo en ratones tratados con receptor de ácido retinoico (RAR) y gen RARã, mientras que los progenitores hematopoyéticos se incrementaron anormalmente (Purton et al., 2006). Algunos genes regulados por retinoides son c-myc, stra-13, hoxb4 y notch 1, todos relacionados a la hematopoyesis (Collins, 2002; Purton et al., 2006).

La presencia de ácido retinoico ha sido asociada al alojamiento $\mathrm{u}$ homing de linfocitos T y B en el intestino delgado (Kim, 2008). Los linfocitos T CD4 memoria y CD8 y linfocitos $\mathrm{B}$ secretores de IgA que se dirigen al intestino expresan la integrina $\alpha 4 \beta 7$, que se une a la molécula 1 de adhesión celular adhesina vascular mucosa (MAdCAM1) expresada en células endoteliales, y el receptor de quimiocina CCR9, que se une a su ligando CCL25 expresado en el epitelio intestinal (Cassani et al., 2011). De esta manera, el AR promueve la expresión de $\alpha 4 \beta 7$ y CCR 9 en linfocitos $\mathrm{T}$ favoreciendo el tropismo intestinal.

Se ha demostrado que el ácido retinoico en conjunción con TGF- $\beta$, promueve la conversión de células $T$ nativas en células $T$ reguladoras (Treg) Foxp3+, lo que evidencia la producción de células Treg periféricas en condiciones normales (Coombes et al., 2007;
Elías et al., 2008). Por tanto, el ácido retinoico es considerado una señal reguladora clave en la inducción de la tolerancia inmune intestinal (Wang et al., 2010) al estimular la producción de TGF- $\beta$ (Maynard et al., 2009) y favorecer la generación de células Treg por células dendríticas (Sun et al., 2007). Es importante recalcar que existen dos tipos de células Treg: las naturales, generadas a nivel tímico, y las inducidas, generadas a partir de células $\mathrm{T}$ nativas en diferentes zonas del organismo, principalmente en el tracto intestinal (Housley et al., 2009).

El presente estudio in vitro tuvo como objetivo evaluar el efecto del ácido retinoico como inmunoestimulante, cuantificando relativamente la expresión de CCR9 y $\alpha 4 \beta 7$ de linfocitos a través de la prueba molecular de la reacción en cadena de la polimerasa a tiempo real (RT-PCR) para determinar indirectamente su acción sobre el establecimiento linfoide a nivel intestinal. Este estudio brinda una visión de una nueva estrategia de control de las enfermedades entéricas para diseñar vacunas que permitan reducir infecciones en el tracto intestinal.

\section{Materiales y MéTOdos}

\section{Lugar de Estudio y Muestras}

Se utilizó sangre entera periférica (10 $\mathrm{ml}$ ) de cinco alpacas adultas del Laboratorio de Química, Bioquímica y Nutrición Animal y el estudio de la expresión génica de CCR9 y $\alpha 4 \beta 7$ se realizó en las instalaciones del Laboratorio de Inmunología de la Facultad de Medicina Veterinaria (FMV) de la Universidad Nacional Mayor de San Marcos (UNMSM) (Lima, Perú).

Las muestras de sangre fueron colectadas en tubos tipo vacutainer con EDTA, por punción de la vena yugular. Los tubos fueron centrifugados a $2000 \mathrm{~g}$ por $5 \mathrm{~min}$ y la parte celular fue vertida a cuatro tubos Falcon conteniendo (1.5 por tubo). Luego se vertió 
$12.5 \mathrm{ml}$ de solución de lisis de eritrocitos (cloruro de amonio) en cada tubo completando a $14 \mathrm{ml}$ de solución total. Todos los tubos fueron agitados manualmente por $5 \mathrm{~min}$ y centrifugados a $1800 \mathrm{~g}$ por $5 \mathrm{~min}$. Se eliminó el sobrenadante y el pellet celular se lavó con suero fisiológico. Finalmente, los tubos fueron centrifugados dos veces a $1800 \mathrm{~g}$ por 5 $\min$.

\section{Cultivo Celular}

Los leucocitos obtenidos fueron disueltos en medio de cultivo RPMI en una concentración de 500000 células por mililitro de medio y cultivados en una placa de cultivo celular de 24 pocillos. Se colocó $1 \mathrm{ml}$ en cada pocillo y se agregó $100 \mu 1$ de ATRA en diversas diluciones para obtener concentraciones de 10,50 y $100 \mu \mathrm{g} / \mathrm{ml}$ de ATRA en cada columna de la placa, cada una con tres repeticiones. Los controles consistieron en células sin aditivos y células con DMSO, ambas con tres repeticiones cada una. El medio de cultivo celular RPMI fue suplementado con $10 \%$ de suero fetal bovino (GIBCO) y penicilina 1\% (Sigma Aldrich).

Las placas fueron incubadas a $37{ }^{\circ} \mathrm{C}$ por 12, 24 y $48 \mathrm{~h}$. La primera cosecha de todo el pocillo se hizo a las $0 \mathrm{~h}$ y luego a las 12,24 y $48 \mathrm{~h}$. El total del medio cosechado fue congelado a $-70{ }^{\circ} \mathrm{C}$ en viales, hasta su uso para la extracción de ARN total.

\section{Extracción de ARN Total}

Se tomó $1 \mathrm{ml}$ de cada uno de los pocillos para la extracción de los ARN totales. Se empleó el reactivo TRIZOL $®$ (Invitrogen, EEUU) siguiendo las instrucciones del fabricante. El ARN total fue precipitado con alcohol isopropílico frío, centrifugado e inmediatamente lavado con etanol frío al $70 \%$. Finalmente, el ARN total fue resuspendido en $60 \mu 1$ de agua libre de nucleasas y almacenado a $0{ }^{\circ} \mathrm{C}$ hasta su uso en el RT-PCR.

\section{Síntesis de ADN Complementario por Transcripción Inversa (RT)}

El ARN obtenido de cada pocillo fue tomado como templado para la síntesis de ADNc, empleándose el kit 'SYBR ${ }^{\circledR}$ GreenER ${ }^{\text {TM }}$ Two-Step qRT-PCR Kit Universal' (Invitrogen, EEUU), siguiendo las instrucciones del fabricante. El volumen final para la Transcripción Reversa (RT) fue de $20 \mu 1$ por reacción/muestra, compuesta por $18 \mu 1$ del master mix (2x RT reaction mix $10 \mu 1 \mathrm{x}$, RT enzyme mix $1 \mu \mathrm{l} \mathrm{n}$, hexámeros al azar $1 \mu \mathrm{l}$ $\mathrm{x} \mathrm{n}, \mathrm{H} 2 \mathrm{O} 6 \mu 1 \mathrm{x}$ n (n=número de muestras a trabajar) más $2 \mu 1$ de ARN templado de cada una de las muestras en los tubos correspondientes.

Las muestras se llevaron al termociclador ABI7500 (Life Technologies, EEUU) programado con el siguiente protocolo: $25^{\circ} \mathrm{C}$ por $10 \mathrm{~min}, 50^{\circ} \mathrm{C}$ por $30 \mathrm{~min}, 85^{\circ} \mathrm{C}$ por $5 \mathrm{~min}$. Seguidamente, las muestras fueron conservadas en hielo por $5 \mathrm{~min}$, se adicionó $1 \mu 1$ de ARNasa H (RNAse H) y se incubaron a $37^{\circ} \mathrm{C}$ por $20 \mathrm{~min}$. El ADNc obtenido fue congelado a $-70{ }^{\circ} \mathrm{C}$ hasta su uso en la reacción de PCR Tiempo Real.

\section{PCR Tiempo Real}

Los oligonucleótidos empleados fueron diseñados en el Laboratorio de Inmunología (FMV-UNMSM) con base de los genes disponibles en el GenBank. Se muestran en el Cuadro 1.

Se empleó el ADNc de cada una de las muestras como templado para la reacción de PCR con el kit 'SuperScript ${ }^{\mathrm{TM}}$ III First-Strand Synthesis SuperMix for qRT-PCR' (Invitrogen, EEUU), siguiendo las recomendaciones del fabricante. Los oligonucleótidos fueron diluidos a $10 \mu \mathrm{M}$ en agua libre de nucleasas como solución de trabajo, colocando el volumen adecuado para obtener una concentración final en la reacción de $0.2 \mu \mathrm{M}$ en todos los casos. La mezcla de reacción 
Cuadro 1. Oligonucleótidos empleados en la RT-PCR tiempo real

\begin{tabular}{lcccccc}
\hline Gen & $\begin{array}{c}\text { Prod } \\
\text { (bp) }\end{array}$ & & Secuencia (5'-3') & Longitud & Tm & GC\% \\
\hline GAPDH & 201 & F & ATC ACT GCC ACC CAG AAG AC & 20 & 60.12 & 55 \\
& & R & GCA CGT CAG ATC CAC AAC AG & 20 & 60.32 & 55 \\
CCR9 & 221 & F & GGA AGC CTG AAG CTG TCA TC & 20 & 60.00 & 55 \\
& & R & TCA CTC CTT CTC CCT CTC CA & 20 & 60.00 & 55 \\
Alpha4 & 200 & F & TTC GGT CTG ATT CTG CTG TG & 20 & 60.00 & 50 \\
& & R & TGT CTT TCG GTT CAC ATC CA & 20 & 60.14 & 45 \\
Beta7 & 214 & F & AAA CAT CCA GCC CAT CTT TG & 20 & 60.08 & 45 \\
& & R & TCT TCT CAG GAT CCC CAC AC & 20 & 60.25 & 55 \\
\hline
\end{tabular}

fue de $20 \mu$ l final $(12.5 \mu$ l Sybr green super mix, $0.5 \mu 1$ primer forward $[10 \mu \mathrm{M}], 0.5 \mu 1$ primer reverse $[10 \mu \mathrm{M}], 0.5 \mu 1 \mathrm{ROX}[1: 10]$, $9.0 \mu 1$ agua libre de nucleasas, $2.0 \mu 1 \mathrm{cDNA})$ Se utilizó el termociclador ABI7500 (Life Technologies, EEUU) programado, según el siguiente protocolo: $50^{\circ} \mathrm{C}$ por $2 \mathrm{~min}, 95^{\circ} \mathrm{C}$ por $10 \mathrm{~min} ; 50$ ciclos de $95^{\circ} \mathrm{C}$ por $15 \mathrm{~s}, 60^{\circ} \mathrm{C}$ por $60 \mathrm{~s}$. Al final de cada ciclo se realizó la medición de la densidad óptica de la placa. Posteriormente se programó la obtención de la temperatura de disociación del producto de en el rango de $65-95{ }^{\circ} \mathrm{C}$ cada $0.3{ }^{\circ} \mathrm{C}, 30$ s. Los resultados fueron observados y analizados utilizando el software ABI 7500 2.0.6 (Life Technologies, EEUU).

\section{Análisis de la Expresión de Genes}

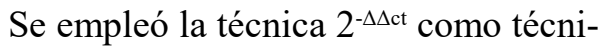
ca de cuantificación de la expresión relativa de genes detectables a través de RT-PCR Tiempo Real (Livak y Smittdgen, 2001). El método se basa en el análisis comparativo de los ciclos ciclo umbral $(\mathrm{Ct})$ de las muestras a estudiar con el $\mathrm{Ct}$ del calibrador (células a las 0 horas sin ningún aditivo). Tanto el $\mathrm{Ct} \mathrm{de}$ los tratamientos como el del calibrador se comparan con el Ct de un control endógeno. Como gen endógeno para la normalización de la cuantificación relativa se utilizó el gen de gliceraldehido-3-fosfato deshidrogenasa (GAPDH).

\section{Análisis Estadístico}

Para evaluar las diferencias entre grupos se calculó el intervalo de confianza al 95\% y los intervalos se emplearon para evaluar las diferencias entre los grupos.

\section{Resultados}

\section{Expresión y Cuantificación Relativa de CCR9}

La expresión del gen de CCR9 muestra un patrón de crecimiento progresivo que se manifiesta por las curvas de amplificación $(\mathrm{Ct})$ en un rango de 29 a 39 (Figura 1). Los productos amplificados tuvieron valores de Tm entre 81.7 y 82.3 (Figura 2), demostrando la amplificación de un producto único y especifico. Todos los tratamientos presentaron niveles detectables de ARNm de este gen.

En la Figura 3 se observa que las concentraciones de 10 y $100 \mu$ g y leucocitos con DMSO muestran una cinética similar aumentando progresivamente con el paso del tiem- 


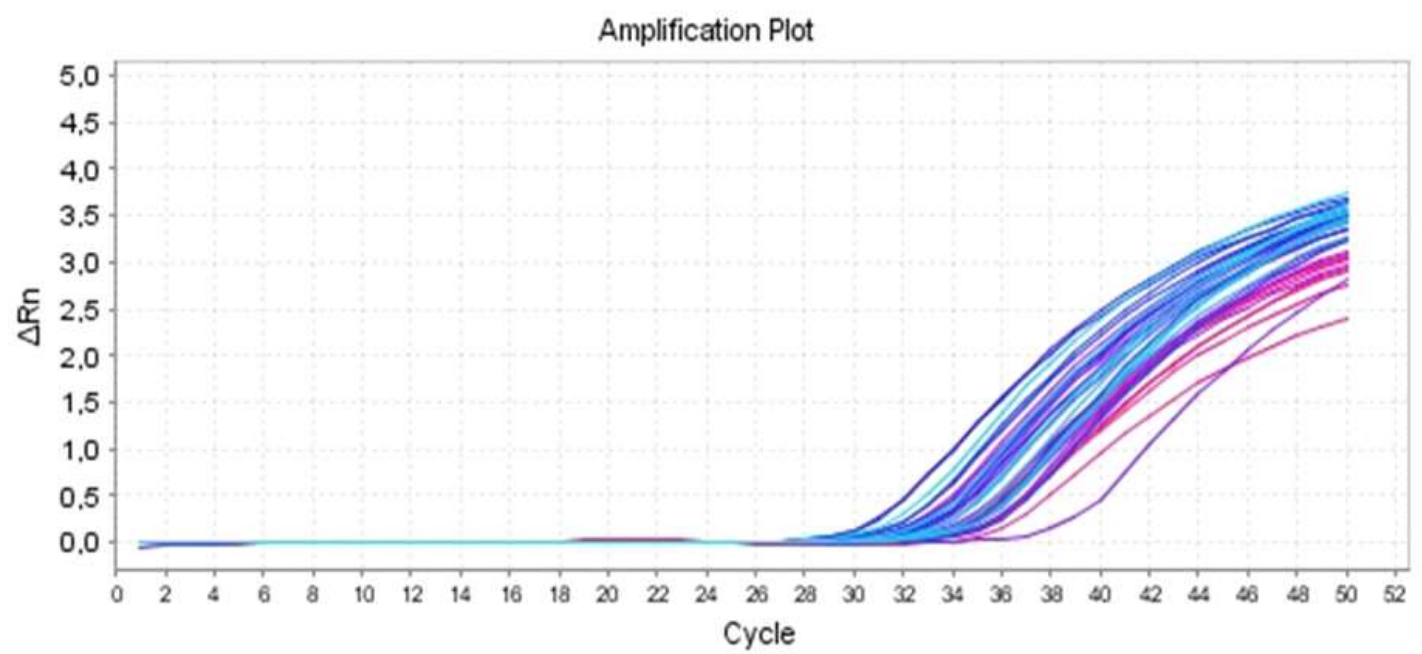

Figura 1. Curva de amplificación (Ct) del gen CCR9 en leucocitos de alpaca. Se observa la línea de corte (threshold). El eje X es el número de ciclo de PCR y el eje Y es el nivel de fluorescencia obtenido después de cada ciclo de amplificación. Cada línea en la curva de color representa una muestra analizada (tres repeticiones por muestra) $(\mathrm{n}=60)$. El color de la línea representa la fila de la placa de pocillos a la cual pertenece cada muestra. Se observa que las muestras alcanzan el valor umbral entre los 29 a 39 ciclos del PCR (rango de valores de Cts)

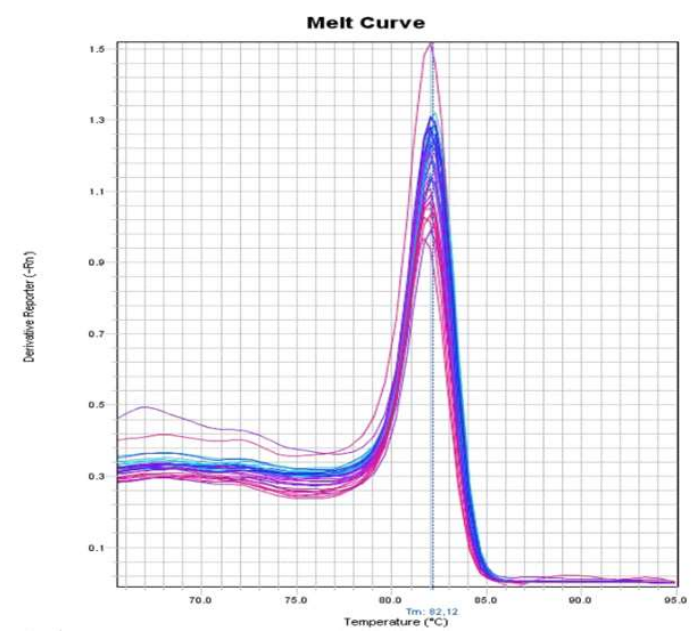

Figura 2. Representación de las curvas de disociación (Tm) de los productos amplificados con el set de oligonucleótidos para el gen CCR9 en leucocitos sanguíneos de alpaca. Los valores de Tm oscilaron entre 81.7 y $82.3^{\circ} \mathrm{C}$

po, mientras que el control y la concentración de $50 \mu \mathrm{g}$ aumentan su expresión hasta las $24 \mathrm{~h}$ para descender a las $48 \mathrm{~h}$. En síntesis, las dosis utilizadas aumentaron su expre- sión hasta las $48 \mathrm{~h}$, tiempo que duró el estudio (excepto el control y la concentración de $50 \mathrm{ig})$.

En el Cuadro 2 se presenta la cuantificación relativa del gen de CCR9. Se determinó que todos los tratamientos con ácido retinoico incrementan la expresión del gen de CCR9, así como el tratamiento con solo DMSO. Las máximas expresiones se dieron a las $48 \mathrm{~h}$ para las concentraciones de $10 \mathrm{y}$ $100 \mu \mathrm{g} / \mathrm{ml}$ de ácido retinoico (105.19 y 86.0 veces con respecto al calibrador, respectivamente) y DMSO (99.18 veces con respecto al calibrador), y a las 24 horas para la concentración de $50 \mu \mathrm{g} / \mathrm{ml}$ de ácido retinoico (62.5 veces con respecto al calibrador) y el control de leucocitos (106.26 veces con respecto al calibrador).

\section{Expresión y Cuantificación Relativa de las Cadenas Polipeptídicas $\alpha 4$ y $\beta 7$}

El gen de la cadena $\alpha 4$ de la integrina $\alpha 4 \beta 7$ solo se incrementó en una exposición a los 10 min de ácido retinoico (hora 0 en este 


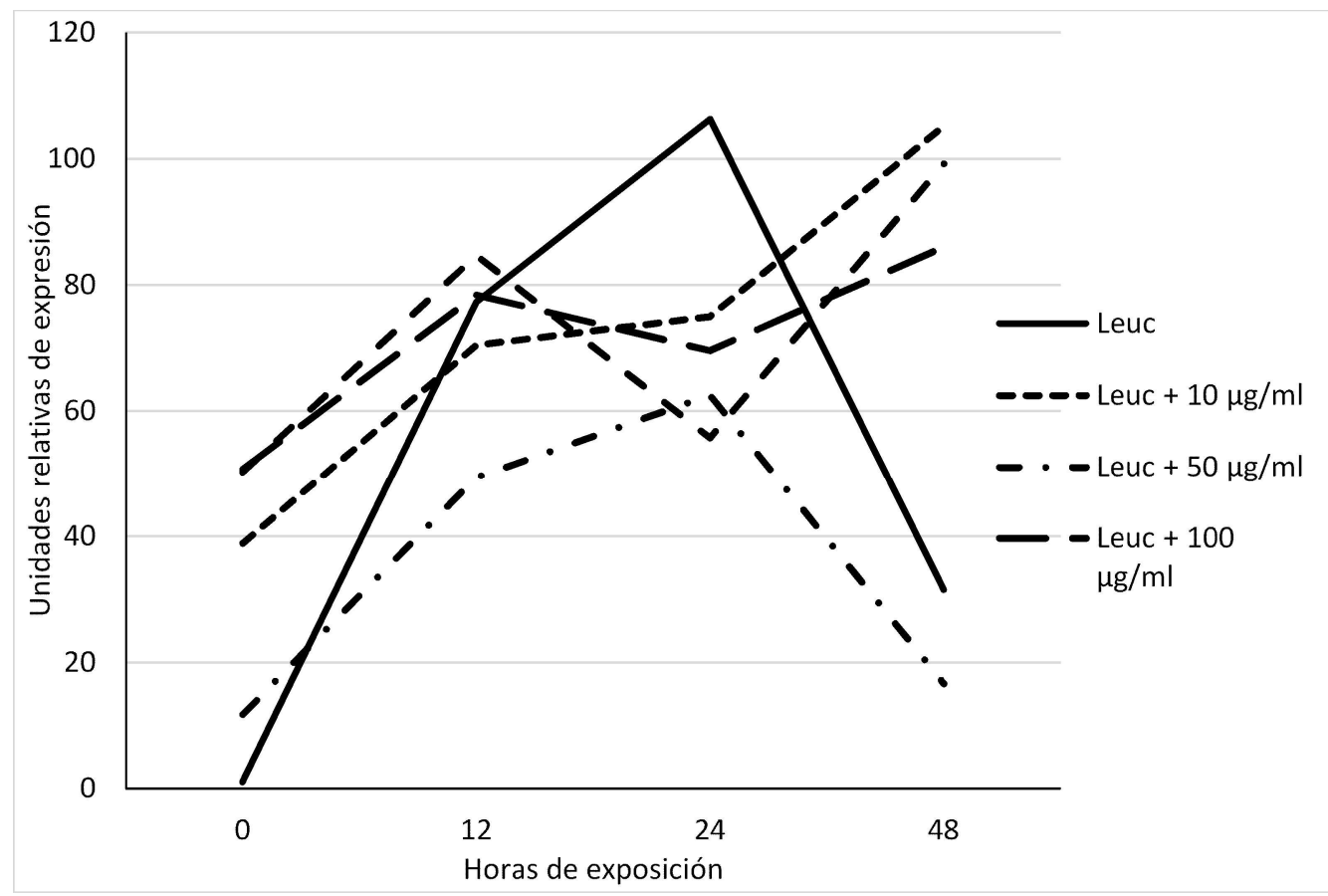

Figura 3. Expresión relativa del gen CCR9. Las líneas representan la cinética de la expresión del gen CCR9 a las $0,12,24$ y $48 \mathrm{~h}$ en leucocitos de alpaca estimulados con diferentes concentraciones de ácido retinoico

Cuadro 2. Niveles relativos de expresión del gen CCR9 (promedio \pm desviación estándar) en leucocitos cultivados in vitro y tratados con DMSO y DMSO + ácido retinoico en varias concentraciones (se consideró el calibrador leucocitos a las 0 horas)

\begin{tabular}{lcccc}
\hline & 0 horas & 12 horas & 24 horas & 48 horas \\
\hline Leucocitos & 1 & $77.2 \pm 65.7$ & $106.3 \pm 93.6$ & $31.5 \pm 14.8$ \\
Leuc $+10 \mu \mathrm{g} / \mathrm{ml}$ & $38.4 \pm 15.2$ & $70.4 \pm 8.6$ & $74.9 \pm 6.5$ & $105.2 \pm 48.9$ \\
Leuc $+50 \mu \mathrm{g} / \mathrm{ml}$ & $11.7 \pm 2.7$ & $49.4 \pm 28.2$ & $62.5 \pm 12.3$ & $16.6 \pm 8.2$ \\
Leuc $+100 \mu \mathrm{g} / \mathrm{ml}$ & $50.7 \pm 27.9$ & $78.3 \pm 6.8$ & $69.5 \pm 33.0$ & $86.0 \pm 20.3$ \\
Leuc + DMSO & $50.2 \pm 25.5$ & $84.6 \pm 0.1$ & $55.7 \pm 8.4$ & $99.2 \pm 40.3$ \\
\hline
\end{tabular}

Cuadro 3. Niveles relativos de expresión del gen $\alpha 4$ (promedio \pm desviación estándar) en leucocitos cultivados in vitro y tratados con DMSO y DMSO + ácido retinoico en varias concentraciones (se consideró el calibrador leucocitos a las 0 horas)

\begin{tabular}{lcccc}
\hline & 0 horas & 12 horas & 24 horas & 48 horas \\
\hline Leucocitos & 1 & 0.33 & 0.11 & 0.04 \\
Leuc $+10 \mu \mathrm{g} / \mathrm{ml}$ & $15.5 \pm 1.0$ & 0 & 0.01 & 0.03 \\
Leuc $+50 \mu \mathrm{g} / \mathrm{ml}$ & $142.7 \pm 0.8$ & 0 & 0.03 & 0.02 \\
Leuc $+100 \mu \mathrm{g} / \mathrm{ml}$ & $325.7 \pm 0.4$ & 0.01 & 0.01 & 0.04 \\
Leuc + DMSO & $125.3 \pm 1.1$ & 0 & 0.01 & 0.13 \\
\hline
\end{tabular}


trabajo), luego de las cuales no se observa la expresión. El incremento es dependiente de la concentración del ácido retinoico, siendo de 1.00 para el control de 15.4 veces para 10 $\mu \mathrm{g} / \mathrm{ml}, 142.7$ veces para $50 \mu \mathrm{g} / \mathrm{ml}$ y 325.7 veces para $100 \mu \mathrm{g} / \mathrm{ml}$. Asimismo, se determinó que el DMSO incrementó la expresión en 125.3 veces el control (Cuadro 3).

No se observó amplificación para el gen $\beta 7$ de la integrina $\alpha 4 \beta 7 \mathrm{y}$, por lo tanto, no se pudo hacer la cuantificación relativa. Pese a que se consideró el último ciclo de la PCR (ciclo 45) como $\mathrm{Ct}$, los valores de cuantificación para este gen se mostraron por debajo de lo normal.

\section{Discusión}

El presente estudio evaluó in vitro el efecto del ácido retinoico (sustancia inmunoestimulante), en tres distintas concentraciones sobre la expresión del receptor CCR9 y la integrina $\alpha 4 \beta 7$ en linfocitos intestinales circulantes de alpaca, utilizando la prueba RT-PCR con cebadores específicos. Esto permitió detectar la presencia de los ARN mensajeros de los tres genes (CCR9, $\alpha 4$ y $\beta 7$ ), los cuales se transcriben independientemente y se unen las cadenas $\alpha 4$ y $\beta 7$ para formar la integrina $\alpha 4 \beta 7$ necesaria para el alojamiento de los linfocitos en la mucosa intestinal (Picarella et al., 1997)

La expresión del gen $\alpha 4$ solo se observó en las muestras de 0 horas de cultivo (tiempo de 10 minuntos entre la cosecha y su congelación) y que es dependiente de la concentración de ácido retinoico (ATRA), elevándose hasta 326 veces más que el control. Esto puede ser debido a que su expresión está condicionada a la presencia de otras moléculas co-estimuladoras, como el factor de crecimiento transformante $\beta$ (TGF- $\beta$ ) y otros compuestos producidos por las células epiteliales de la mucosa intestinal (Zhang y Bevan, 2013).
La expresión del gen $\alpha 4$ indicaría que existen células estimuladas en la mucosa intestinal que están migrando por el torrente sanguíneo. Estas células son estimuladas por el ácido retinoico induciendo su expresión en los primeros 10 minutos, pero que luego desaparecen al no encontrar el nicho adecuado para establecerse. La presencia de leucocitos diferenciados en la circulación sanguínea de las alpacas y estimulados por ATRA se confirma en el trabajo de More (2013), donde se demuestra el incremento de expresión de genes de varias interleucinas cuando son estimuladas con distintas concentraciones de ATRA y antígenos clostridiales in vitro.

La expresión del gen $\beta 7$ no se manifestó en ninguna concentración de ATRA, indicando que este gen no es estimulado por esta molécula. Este gen se expresa cuando los linfocitos entran al nicho de la mucosa intestinal, siendo estimulados en presencia de TGF- $\beta$ y metabolitos del ácido retinoico producido por las células dendríticas. La falta de activación por solo ATRA indica que debe ser por vías de co-estimulación en conjunto (Sheen et al., 2013). Es importante indicar que previamente se realizó un RT-PCR con cinco muestras de mucosa intestinal de alpaca donde se determinó la expresión de los genes de la cadena polipeptida de á4, â7 y CCR9 que sirvió para la estandarización de esta prueba.

En general se puede afirmar que la integrina $\alpha 4 \beta 7$ no se expresa en el cultivo in vitro de leucocitos de alpacas en presencia de ATRA a distintas concentraciones y requieren que co-estimulen su expresión moléculas como el TGF- $\beta$, que es producido en la mucosa intestinal y que junto al ácido retinoico generan el ambiente ideal para expresión de las proteínas del alojamiento linfoide (Homing linfoide) en la mucosa intestinal, sumado a efectos secundarios no determinados (Biancheri et al., 2013). Aparentemente el TGF- $\beta$ sería un factor importante a tener en cuenta para la expresión constante de los genes $\alpha 4$ y $\beta 7$, complementando de esta ma- 
nera la expresión de la integrina $\alpha 4 \beta 7$, la cual interviene junto con CCR9 en el homing de los linfocitos $\mathrm{T}$ activados hacia la mucosa intestinal (Zhang y Bevan, 2013).

La expresión máxima de CCR9 se evidenció a las 48 horas para las concentraciones de 10 y $100 \mu \mathrm{g} / \mathrm{ml}$ de ácido retinoico y DMSO, lo que podría deberse a la liberación de moléculas de alarma celular liberadas al medio por la muerte y lisis de leucocitos en el cultivo. Además, el control celular presentó también expresiones crecientes de CCR9 indicando que este receptor tiene, además, otras funciones no determinadas en la sobrevivencia celular. Por otra parte, el incremento en la expresión del gen de CCR9 en presencia de DMSO se observó en los primeros 10 minutos. Es muy probable que exista una respuesta inmunológica en primera instancia hacia este agente extraño, produciéndose quimiocinas que estimulen la expresión de dicho receptor. No obstante, esta expresión disminuye con el tiempo de incubación, debido a que el DMSO afecta a la viabilidad celular por cierta citotoxicidad (Da Violante et al., 2002).

Se ha demostrado que la quimiocina CCL25 /TECK es el ligando para CCR9 en los linfocitos B y $\mathrm{T}$ y que se localiza en el epitelio de las criptas del yeyuno y el íleon (Kunkel et al., 2000). Se conoce que CCL25 se expresa también en células endoteliales y en subconjuntos de células en la lámina propia del intestino delgado (Papadakis et al., 2000). De esta manera, CCL25/TECK demuestra un rol importante en la migración de linfocitos en condiciones inflamatorias y no inflamatorias, siendo determinante para el homing intestinal (Hosoe et al., 2004).

Se sabe, además, que el CCR9 también tiene como ligandos a CCL-2 (MCP-1) y CCL7 (MCP-3) (Mackay, 2001). Por tanto, la expresión de CCR9 demostrada en el presente estudio evidencia que no solo el homing intestinal juega un papel importante en la expresión de este receptor, sino que además existen ciertas quimiocinas que se expresan en una variedad de células cuando ocurre un evento de estrés oxidativo celular, tal es el caso de la quimiocina CCL2 (MCP-1), la cual podría estar estimulando la expresión de este receptor (Deshmane et al., 2009).

En este estudio in vitro con sangre periférica de alpaca no se pudo comprobar el rol que desempeñaría ATRA como inmunoestimulante hallado en otros estudios in vivo e in vitro. Existe una expresión evidente del receptor de CCR9 en todos los tratamientos, demostrado a través del método de cuantificación relativa, de allí que es probable que el incremento en la expresión de CCR9 pueda deberse a otros factores que estén estimulando su expresión, como el estrés oxidativo celular o el mismo DMSO. Estos hallazgos contrastan con los pocos estudios in vitro que evalúan el ácido retinoico como inmunoestimulante en mucosa intestinal de alpacas (More, 2013; Lázaro et al., 2015) en los que se observa una expresión marcada de genes de interleucinas e Ig A, respectivamente.

El grupo de tratamiento de leucocitos con DMSO es el que exhibe una desviación estándar considerablemente elevada. Mientras más elevado sea este valor en un tratamiento significa que la expresión de los genes evaluados es menor, ya que se estaría enmascarando la expresión por la elevada variabilidad. La desviación estándar elevada en muchos de los tratamientos se debe a la cantidad de células que están muriendo; es decir, en un pocillo mueren más células que en otros, resultando en una alta variabilidad entre pocillos. Las causas de la muerte celular pueden ser diversas; por ejemplo, por lisis de los leucocitos recuperados, por pérdidas de células durante el cultivo, y por el tiempo transcurrido entre la inoculación y la cosecha (Olofsson, 1991). Es probable que las células reaccionen al DMSO, expresando estas proteínas en su superficie en respuesta a un factor extraño (Platas, 2015). 
Todas las concentraciones de ácido retinoico evaluadas aumentaron la expresión de CCR9 hasta las 48 horas, tiempo que duró el estudio, excepto para el grupo control y la concentración de $50 \mu \mathrm{g}$ de ácido retinoico. La explicación para estos dos últimos casos está relacionado a la cantidad de células presentes en los pocillos; donde es probable el número de células inoculadas haya sido mínimo en esos tratamientos, asociado también a la vida media del leucocito. Esto pudo haber ocasionado que los genes evaluados no pudieron ser detectados por la PCR (Williams et al., 1992).

Se debe tener en cuenta que en el cultivo hay una dinámica de expresiones muy activa existiendo mucha interacción celular. A esto se le suma que los leucocitos son difíciles de cultivar y van muriendo en forma progresiva. Sin embargo, hay leucocitos que se pueden fijar dentro de las placas como los macrófagos, monocitos y células dendríticas. Estos últimas se pueden adherir a la placa al igual que los macrófagos. Esta es una de las razones de la cinética de la expresión de CCR9 la cual aumenta a las 12 horas para disminuir a las 24 horas y volver a aumentar a las 48 horas. Eso explica el primer aumento y descenso de la expresión, respectivamente. Por otro lado, las células dendríticas y macrófagos que se fijan a las placas pueden vivir más tiempo y esto explicaría el segundo aumento. Por consiguiente, el aumento de expresión a las 48 horas estaría indicando que algunas células se están adhiriendo y que permanecen vivas en el cultivo. La adhesión de las células al pocillo podría inducir la expresión de nuevos genotipos y uno de ellos podría ser CCR9, aunque principalmente se sabe que solo los linfocitos expresan CCR9. No se ha establecido si otras células pueden expresar también estos genes (Wilson et al., 2005). Los resultados evidencian una imagen muy amplia de muchas subpoblaciones que podrían distinguirse si solamente se trabajase con linfocitos. Hay técnicas especializadas como la citometría de flujo para hacer esta separación (Barrera et al., 2004).
El DMSO, solvente utilizado para la dilución del ácido retinoico y que se evidencia que tuvo un efecto sobre la expresión del receptor CCR9, es conocido y utilizado como agente criopreservante intracelular (al igual que el glicerol), minimizando la formación de hielo intracelular y reduciendo el daño celular. El DMSO es un líquido orgánico que contiene sulfuro con atribuciones de múltiples propiedades terapéuticas. Es usado comúnmente como disolvente orgánico en la industria, y como medicamento. Tiene la propiedad de atravesar rápidamente las membranas celulares, sirviendo también como acarreador de drogas. Es un disolvente altamente polar, por lo que es miscible en agua, alcoholes y cetonas. Se requiere investigar más sobre el mecanismo de este disolvente y de qué manera estaría alterando el genotipo de las células para la expresión de receptores en su membrana.

\section{Conclusiones}

- Se observa expresión del receptor de quimiocina CCR9 en los leucocitos de alpaca cultivados in vitro estimulados por ácido retinoico en las dosis de 10, 50 y $100 \mu \mathrm{g} / \mathrm{ml}$ a las 0,12 y 24 horas.

- No se observa estimulación con ácido retinoico para la expresión de los genes de la integrina $\alpha 4 \beta 7$ en leucocitos de alpacas obtenidos de sangre periférica cultivados in vitro.

- No se evidencia el efecto del ácido retinoico sobre la expresión de receptor de quimiocina CCR9 en los leucocitos de alpaca cultivados in vitro.

- No se observa estimulación con ácido retinoico para la expresión de los genes de la integrina $\alpha 4 \beta 7$ en leucocitos de alpacas obtenidos de sangre periférica cultivados in vitro.

\section{Agradecimientos}

Se agradece al INNOVATE PERU Proyecto N. ${ }^{\circ} 180$ FINCYT 2013 por el financiamiento del trabajo de investigación. 


\section{Literatura Citada}

1. Barrera L, Drago M, Zamora A, Sainz T, Mendoza F. 2004. Citometría de flujo: vínculo entre la investigación básica y la aplicación clínica. Rev Inst Nal Enf Resp Mex 17(1): 42-55.

2. Biancheri P, Giuffrida P, Docena GH, MacDonald TT, Corazza GR, Di Sabatino A. 2013. The role of transforming growth factor (TGF)- $\beta$ in modulating the immune response and fibrogenesis in the gut. Cytokine Growth Factor Rev 25: 45-55. doi: 10.1016/ j.cytogfr.2013.11.001

3. Cassani B, Villablanca EJ, Quintana FJ, Love PE, Lacy-Hulbert A, Blaner WS, Sparwasser T, et al. 2011. Guttropic $T$ cells that express integrin $\alpha 4 \beta 7$ and CCR9 are required for induction of oral immune tolerance in mice. Gastroenterology 141: 2109-2118. doi: 10.1053/j.gastro.2011.09.015

4. Collins SJ. 2002. The role of retinoids and retinoic acid receptors in normal hematopoiesis. Leukemia 16: 1896-1905. doi: 10.1038/sj.leu.2402718

5. Coombes JL, Siddiqui KR, ArancibiaCárcamo CV, Hall J, Sun CM, Belkaid Y, Powrie F. 2007. A functionally specialized population of mucosal $\mathrm{CD}_{103^{+}}$DCs induces Foxp $3^{+}$ regulatory $T$ cells via a TGF- $\beta$ and retinoic acid-dependent mechanism. J Exp Med 204: 1757-1764. doi: 10.1084/ jem.20070590

6. Da Violante G, Zerrouk N, Richard L, Provot G, Chaymeil JC, Arnauld P. 2002. Evaluation of the cytotoxicity effect of dimethyl sulfoxide (DMSO) on Caco2/TC7 colon tumor cell cultures. Biol Pharm Bull 25: 1600-1603. doi: 10.1248/bpb.25.1600

7. Deshmane $S$, Kremlev $S$, Amini $S$, Sawaya B. 2009. Monocyte chemoattractant protein-1 (MCP-1): an overview. J Interferon Cytokine Res 29: 313-326. doi: 10.1089/jir.2008.0027
8. Elias KM, Laurence A, Davidson TS, Stephens G, Kanno Y, Shevach EM, O'Shea JJ. 2008. Retinoic acid inhibits Th17 polarization and enhances FoxP3 expression through a STAT-3/STAT-5 independent signaling pathway. Blood 111: 1013-1020. doi: 10.1182/blood-200706-096438

9. Hosoe N, Miura S, Watanabe C, Tsuzuki Y, Hokari R, Oyama T, Fujiyama Y. 2004. Demonstration of functional role of TECK/CCL25 in T lymphocyte-endothelium interaction in inflamed and uninflamed intestinal mucosa. Am J Physiol Gastrointest Liver Physiol 286: G458-466. doi: 10.1152/ ajpgi.00167.2003

10. Housley WJ, O'Connor CA, Nichols F, Puddington L, Lingenheld EG, Zhu L, Clark RB. 2009. PPAR $\gamma$ regulates retinoic acid-mediated DC induction of Tregs. J Leukoc Biol 86: 293-301. doi: 10.1189/jlb.1208733

11. Iwata M, Hirakiyama A, Eshima Y, Kagechika H, Kato C, Song SY. 2004. Retinoic acid imprints gut-homing specificity on T cells. Immunity 21: 527 528. doi: 10.1016/j.immuni.2004.08.011

12. Kim CH. 2008. Roles of retinoic acid in induction of immunity and immune tolerance. Endocr Metab Immune Disord Drug Targets 8: 289-294. doi: 10.2174/ 187153008786848312

13. Kunkel EJ, Campbell JJ, Haraldsen G, Pan J, Boisvert J, Roberts AI, Ebert $E C$, et al. 2000. Lymphocyte CC chemokine receptor 9 and epithelial thymus expressed chemokine (TECK) expression distinguish the small intestinal immune compartment : epithelial expression of tissue-pecific chemokines as an organizing principle in regional immunity. J Exp Med 192 : 761-768.

14. Lázaro R, Manchego A, Pezo D, More $J$, Castro G, Sauce J, Sandoval N. 2015. Efecto de antígenos de Clostridium perfringens y ácido retinoico sobre la expresión de IgA en la mucosa intestinal de crías de alpacas 
(Vicugna pacos). Rev Inv Vet Perú 26: 689-697. doi: 10.15381/rivep.v26i4.11216

15. Leung AY, Verfaillie CM. 2005. Alltrans retinoic acid (ATRA) enhances maintenance of primitive human hematopoietic progenitors and skews them towards myeloid differentiation in a stroma-noncontact culture system. Exp Hematol 33: 422-427. doi: 10.1016/ j.exphem.2004.12.007

16. Livak KJ, Schmittgen TD. 2001. Analysis of relative gene expression data using real-time quantitative PCR and the $2^{-\triangle \Delta C T}$ method. Methods 25: 402-408. doi: 10.1006/meth.2001.1262

17. Mackay CR. 2001. Chemokines: immunology's high impact factors. Nat Immunol 2: 95-101. doi: 10.1038/84298

18. Maynard CL, Hatton RD, Helms WS, Oliver JR, Stephensen CB, Weaver CT. 2009. Contrasting roles for all-trans retinoic acid in TGF- $\beta$-mediated induction of Foxp3 and IL10 genes in developing regulatory T cells. J Exp Med 206: 343357. doi: 10.1084/jem. 20080950

19. More J. 2013. Efecto de antígenos clostridiales con ácido retinoico sobre la expresión de citoquinas de la respuesta inmune humoral y celular de la mucosa intestinal de crías de alpacas (Vicugna pacos). Tesis de Maestría. Lima: Univ Nacional Mayor de San Marcos. 104 p.

20. Olofsson T. 1991. Growth regulation of hematopoietic cells: an overview. Acta Oncol 30: 889-902. doi: 10.3109/ 02841869109088241

21. Papadakis KA, Prehn J, Nelson V, Cheng L Binder $S W$, Ponath PD, Andrew DP, Targan SR. 2000. The role of thymus expressed chemokine and its receptor CCR9 on lymphocytes in the regional specialization of the mucosa immune system. J Immunol 165: 5069-5076

22. Picarella D, Hurlbut P, Rottman J, Shi X, Butcher E, Ringler DJ. 1997. Monoclonal antibodies specific for beta7 integrin and mucosal addressin cell - adhesion molecule-1 (MAdCAM-1) reduce inflammation in the colon of scid mice reconstituted with CD45RBhigh CD4+ T cells. J Immunol 158: 2099-2106.

23. Platas JH. 2015. Uso de dimetilsufóxido y glicerol para la preservación de células endocrinas. Tesis de Médico Veterinario Zootecnista. México: Univ Veracruzana. $34 \mathrm{p}$.

24. Purton LE, Bernstein ID, Collins SJ. 2000. All-trans retinoic acid enhances the long-term repopulating activity of cultured hematopoietic stem cells. Blood 95: 470-477.

25. Purton LE, Dworkin S, Olsen GH, Walkley CR, Fabb SA, Collins SJ, Chambon P. 2006. RAR $\gamma$ is critical for maintaining a balance between hematopoietic stem cell self-renewal and differentiation. J Exp Med 203: 12831293. doi: $10.1084 / \mathrm{jem} .20052105$

26. Sheen YY, Kim MJ, Park SA, Park SY, Nam JS. 2013. Targeting the transforming growth factor $-\beta$ signaling in cancer therapy. Biomol Ther 21:323-331.

27. Sun CM, Hall JA, Blank RB, Bouladoux N, Oukka M, Mora JR, Belkaid Y. 2007. Small intestine lamina propria dendritic cells promote de novo generation of Foxp3 T reg cells via retinoic acid. J Exp Med 204: 1775-1785. doi: 10.1084/jem.20070602

28. Wang C, Kang SG, HogenEsch $H$, Love PE, Kim CH. 2010. Retinoic acid determines the precice tissue tropism of inflammatory Th17 cells in the intestine. J Immunol 184: 5519-5526. doi: 10.4049/ jimmunol.0903942

29. Williams W, Rosenbaum H, Weiner D. 1992. Effect of RNA concentration on cDNA synthesis for DNA amplification. Genome Res 2: 86-88.

30. Wilson C, Clegg R, Leavesley D, Pearcy M. 2005. Mediation of biomaterial-cell interactions by adsorbed proteins: a review. Tissue Eng 1-2: 1-18. doi: 10.1089/ten.2005.11.1 
31. Zhang N, Bevan M. 2013. Transforming growth factor- $\beta$ signaling controls the formation and maintenance of gut resident memory $\mathrm{T}$ cells by regulating migration and retention. Immunity 39 : 687-696. doi: 10.1016/j.immuni.2013.08.019
32. Zeng R, Oderup C, Yuan R, Lee M, Habtezion A, Hadeiba H, Butcher EC. 2013. Retinoic acid regulates the development of a gut-homing precursor for intestinal dendritic cells. Mucosal Immunol 6: 847-856. doi: 10.1038/mi.2012.123 